\title{
Neuroblastoma of the Urinary Bladder in an Infant
}

\author{
Ahmed Mohamed ${ }^{1 \odot}$ Quentin Campbell-Hewson ${ }^{2}$ Hany O. S. Gabra ${ }^{2}$ \\ ${ }^{1}$ Department of Paediatric Surgery, University Hospitals of Leicester \\ NHS Trust, Leicester Royal Infirmary Infirmary Square Leicester, \\ Leicester, United Kingdom of Great Britain and Northern Ireland \\ 2 Department of Paediatric Surgery, Royal Victoria Infirmary, \\ Newcastle, United Kingdom \\ Address for correspondence Ahmed Mohamed, Department of \\ Paediatric Surgery, University Hospitals of Leicester NHS Trust, \\ Leicester Royal Infirmary Infirmary Square Leicester, Leicester LE1 \\ 5WW, United Kingdom of Great Britain and Northern Ireland \\ (e-mail: dr.ahmed.osama.salama@gmail.com).
}

Eur J Pediatr Surg Rep 2019;7:e32-e35.

\begin{abstract}
Keywords

- neuroblastoma

- pediatric oncology

- urinary bladder

- pediatric tumors

As it originates from neural crest cells, Neuroblastoma (NBL) can arise anywhere along the sympathetic chain. However, its occurrence in the urinary bladder (UB) is extremely rare. We present a case of an incidentally diagnosed pelvic NBL arising from the dome of the UB in a 7-month-old infant. The mass was treated with surgical excision only after being classified as a very low risk group according to the International Neuroblastoma Risk Group staging system. The patient was disease free after 5 years of follow-up. Although rare, we suggest that NBL should be considered in the differential diagnosis of UB masses in children and investigated accordingly.
\end{abstract}

\section{New Insights and the Importance for the Pediatric Surgeon}

Neuroblastoma should be considered in the differential diagnosis of urinary bladder masses occurring in the pediatric age group, especially when arising from the dome.

\section{Introduction}

Neuroblastoma (NBL) is the commonest solid tumor of infancy and the second most common extracranial malignant tumor of childhood. ${ }^{1}$ Most commonly occurring in the abdomen in $65 \%$ of cases, NBL can also develop in the paraspinal sympathetic ganglia at other sites including the chest $(20 \%)$, neck $(5 \%)$, and pelvis $(5 \%)^{2}$. Forty percent of symptomatic patients are younger than 1 year at the time of diagnosis and with a slight male predominance (1.2:1). ${ }^{1} \mathrm{NBL}$ affects 1 in 7,000 children and is thought to be responsible for $15 \%$ of oncology-related mortality in childhood. ${ }^{3}$ We report an unusual case of NBL arising from the dome of the urinary bladder (UB) of a 7-month-old infant. To the best of our knowledge, this is only the ninth reported case of a neuroblastic tumor originating primarily from the UB.

DDr. Ahmed Mohamed's ORCID is https://orcid.org/0000-00021930-5707.

received

December 21, 2018

accepted after revision

April 28, 2019

\section{Case Report}

Our patient is a 7-month-old previously healthy boy, who was referred to our tertiary center with an incidental finding of a pelvic mass on ultrasound (US) that was performed as part of the investigative pathway for the febrile urosepsis he was being managed for.

Clinical examination and laboratory work-up were essentially unremarkable. US showed a well-circumscribed, solid, polypoid mass arising from the UB fundus, measuring $2 \mathrm{~cm}$ in diameter, with hypervascularity on color Doppler ( - Fig. 1A). Magnetic resonance imaging (MRI) showed a $(20 \times 18 \times 17 \mathrm{~mm})$ well-defined, homogenous, solid mass arising from the middle/left side of the dome of UB ( - Fig. 1B). A cystoscopic biopsy was attempted but proved to be difficult as the mass was completely submucosal and not clearly visible.

We proceeded to excisional biopsy through an extended suprapubic incision. The dome of the UB was opened, and the tumor felt elastic, firm, and homogenous ( - Fig. 2). The mass

\footnotetext{
(c) 2019 Georg Thieme Verlag KG Stuttgart · New York
}

License terms

10.1055/s-0039-1692192. ISSN 2194-7619.

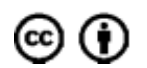



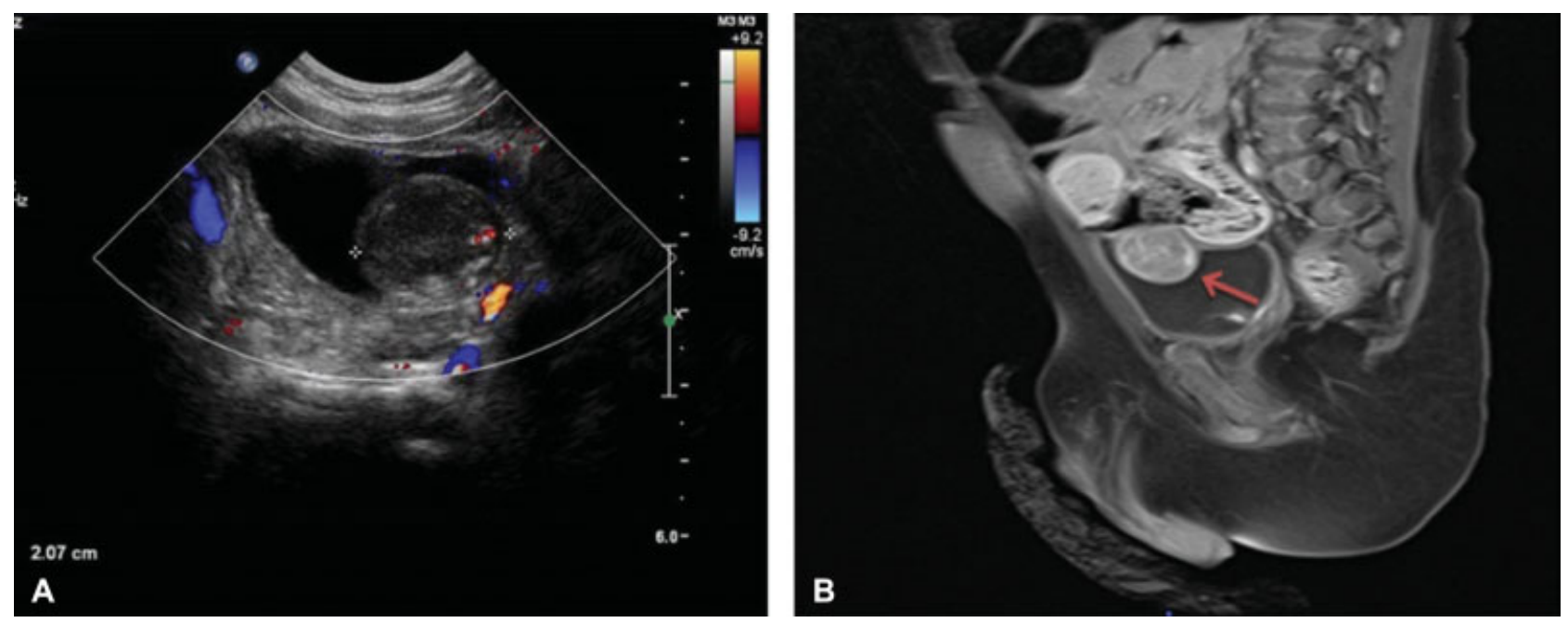

Fig. 1 (A) Incidentally discovered urinary bladder mass. (B) Magnetic resonance imaging (MRI) showing solid mass arising from the urinary bladder fundus (arrow).

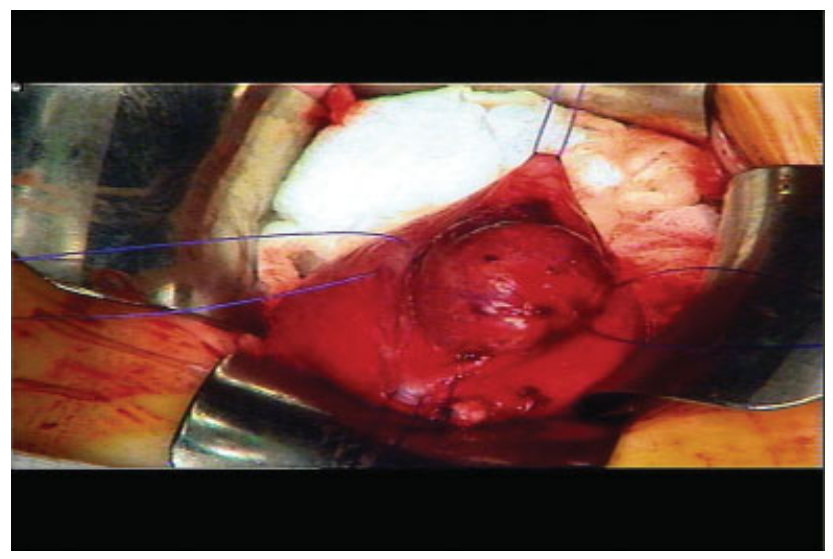

Fig. 2 Intraoperative view of the urinary bladder mass.

was excised completely with grossly negative margins, and the recovery period was uneventful. Histopathology was consistent with a completely excised, poorly differentiated NBL with low mitosis-karyorrhexis index and favorable histology, as per Shimada's classification. Multiplex ligation dependent probe amplification analysis showed no evidence of proto-oncogene N-myc (MYCN) amplification or any segmental chromosomal abnormalities.

Further assessment was made for metastatic disease, including bone scan, bone marrow biopsy, and MIBG (metaiodobenzylguanidine) scan, which were all negative. Urine creatinine, HMMA (4-hydroxy-3-methoxy mandelic acid)/creatinine, and homovanillic acid (HVA)/creatinine ratios were all within normal limits.

Due to favorable prognostic factors, our patient was classified as a very low risk group according to the International Neuroblastoma Risk Group staging system (INRGSS) and was treated by surgical excision only. Annual follow-up with clinical examination and two MRI scans performed after 1 and 3 years postoperatively revealed no evidence of recurrence or residual tumor. The patient remained asymptomatic throughout and was discharged from follow-up after 5 years.

\section{Discussion}

NBL is the most common extracranial solid tumor of childhood. ${ }^{4} \mathrm{NBL}$ of the UB, however, is an almost unknown entity. As it originates from neural crest cells, NBL can occur anywhere along the sympathetic chain and has a median age of presentation of 18 to 23 months. ${ }^{1,5}$ Most primary tumors occur in the abdomen in $65 \%$ of cases, commonly from the adrenal glands, and 15 to $20 \%$ occur in the thorax, whereas pelvic presentation is seen in approximately $5 \%$ of cases. ${ }^{2,6}$ Rare sites of primary NBL include the orbit, lung, and genitourinary tract. ${ }^{7}$ Tumors arising from the retroperitoneal or pelvic space are more frequently diagnosed on routine mass screening such as the Japanese program, which started in 1984, in which urine samples from infants aged 6 months were tested for HVA and vanilmandelic (VMA) acid by high-performance liquid chromatography. ${ }^{8,9}$

Other than cases diagnosed by screening, bladder NBL can present with microscopic hematuria and/or the presence of a palpable mass on physical examination. ${ }^{10,11}$ Our patient was asymptomatic, most likely due to the early incidental diagnosis. Literature review suggests eight other similar reported cases to date. Six patients were under 15 months of age, ${ }^{12}$ whereas the other two patients were 3 and 5 years of age, respectively. ${ }^{13,14}$ Interestingly, in six out of eight reported cases, the masses originated from the dome of the UB. ${ }^{12-14}$ The two other reported sites of pathology were the lateral and the anterior walls of the UB. ${ }^{12-14}$ All pathological subtypes of the NBL spectrum were described with four patients exhibiting poorly differentiating NBL, one case of stroma-poor differentiating NBL, one ganglioneuroblastoma (GNBL), a single ganglioneuroma (GN) and one case was not specified. ${ }^{12-14}$

-Table 1 summarizes the histological classification, MYCN amplification, chromosomal abnormalities, and treatment given for the described cases. All cases had a good outcome with no reported mortality. ${ }^{12-14}$

The preoperative staging system in NBL is the INRGSS of 2009, which has simplified the staging into L1, L2, M, and 
Table 1 Characteristics of eight reported cases of neuroblastoma of the urinary bladder

\begin{tabular}{|c|c|c|c|c|c|c|c|c|}
\hline Case & Age & Histology & $\begin{array}{l}\text { Shimada's } \\
\text { classification }\end{array}$ & MYCN & $\begin{array}{l}\text { Chromosomal } \\
\text { deletions }\end{array}$ & Ploidy & Surgery & Chemotherapy \\
\hline 1 & $3 \mathrm{mo}$ & $\begin{array}{l}\text { Poorly } \\
\text { differentiated } \\
\text { NBL }\end{array}$ & $\begin{array}{l}\text { Favorable } \\
\text { histology }\end{array}$ & Amp & Yes & Diploidy & $\begin{array}{l}\text { Partial } \\
\text { cystectomy }\end{array}$ & $\begin{array}{l}\text { Adjuvant after } \\
\text { recurrence }\end{array}$ \\
\hline 2 & $4 \mathrm{mo}$ & $\begin{array}{l}\text { Poorly } \\
\text { differentiated } \\
\text { NBL }\end{array}$ & $\begin{array}{l}\text { Favorable } \\
\text { histology }\end{array}$ & NA & - & Aneuploidy & $\begin{array}{l}\text { Partial } \\
\text { cystectomy }\end{array}$ & Adjuvant \\
\hline 3 & $4 \mathrm{mo}$ & GNBL & - & - & - & - & $\begin{array}{l}\text { Partial } \\
\text { cystectomy }\end{array}$ & No \\
\hline 4 & $7 \mathrm{mo}$ & $\begin{array}{l}\text { Poorly } \\
\text { differentiated } \\
\text { NBL }\end{array}$ & $\begin{array}{l}\text { Favorable } \\
\text { histology }\end{array}$ & NA & - & - & $\begin{array}{l}\text { Partial } \\
\text { cystectomy }\end{array}$ & No \\
\hline 5 & $8 \mathrm{mo}$ & $\begin{array}{l}\text { Poorly } \\
\text { differentiated } \\
\text { NBL }\end{array}$ & $\begin{array}{l}\text { Favorable } \\
\text { histology }\end{array}$ & NA & No & - & $\begin{array}{l}\text { Partial } \\
\text { cystectomy }\end{array}$ & No \\
\hline 6 & $15 \mathrm{mo}$ & $\begin{array}{l}\text { NBL } \\
\text { (not specified) }\end{array}$ & $\begin{array}{l}\text { Favorable } \\
\text { histology }\end{array}$ & NA & - & - & $\begin{array}{l}\text { Partial } \\
\text { cystectomy }\end{array}$ & Neoadjuvant \\
\hline 7 & $3 y$ & $\begin{array}{l}\text { Differentiating } \\
\text { NBL }\end{array}$ & $\begin{array}{l}\text { Favorable } \\
\text { histology }\end{array}$ & NA & - & - & $\begin{array}{l}\text { Partial } \\
\text { cystectomy }\end{array}$ & No \\
\hline 8 & $5 y$ & GN & - & - & - & - & $\begin{array}{l}\text { Transurethral } \\
\text { resection }\end{array}$ & No \\
\hline
\end{tabular}

Abbreviations: Amp, amplified; GN, ganglioneuroma; GNBL, ganglioneuroblastoma; MYCN, proto-oncogene N-myc; NA, not Amplified; NBL, neuroblastoma.

MS. ${ }^{15}$ By a combination of postoperative staging and other prognostic factors including age, Shimada grade, histological features, and genetics, patients are grouped into four prognostic risk groups: very low, low, moderate, and high. ${ }^{15,16}$ Postsurgery, NBL is classically staged from 1 to 4 according to the 1993 revised International Neuroblastoma Staging System. ${ }^{17}$

NBL is known to exhibit the highest rate of spontaneous regression among malignant tumors. ${ }^{18}$ Ghazali $^{19}$ first reported a series of pelvic NBL that underwent spontaneous regression and maturation. Subsequent studies adopting a watchful waiting approach in patients with NBL detected by screening or during infancy report high rates of regression. ${ }^{20,21}$ Therefore, although active intervention is the mainstay of treatment, a wait-and-see approach avoiding surgical procedures and chemotherapy in localized NBL diagnosed in early infancy has been suggested.

Treatment strategies for NBL include surgery, chemotherapy, and/or radiation. Stem cell transplant and immunotherapy are reserved for advanced or recurrent disease. Low and intermediate risk groups have a 95\% survival rate with the use of surgery and/or chemotherapy. High-risk groups with combination therapy have a survival between 40 and $50 \%{ }^{5}$

Our patient was stage L1 by INRGSS and because of the favorable prognostic factors was put in the very low-risk group, which is amenable to treatment by surgical excision solely. Annual clinical examination and two postoperative MRI scans revealed no evidence of recurrent or residual tumor. We discharged the patient after 5 years of follow-up.

\section{Conclusion}

Although rare, NBL should be considered in the differential diagnosis of pediatric urinary bladder masses, especially when arising from the dome.

\section{Conflict of interest}

None.

\section{Acknowledgment}

None.

Note

Dr. Ahmed has Membership of Royal College of Surgeons (MRCS).

\section{References}

1 Park JR, Eggert A, Caron H. Neuroblastoma: biology, prognosis, and treatment. Hematol Oncol Clin North Am 2010;24(01):65-86

2 Janoueix-Lerosey I, Schleiermacher G, Delattre O. Molecular pathogenesis of peripheral neuroblastic tumors. Oncogene 2010;29(11):1566-1579

3 Shuangshoti S, Shuangshoti S, Nuchprayoon I, et al. Natural course of low risk neuroblastoma. Pediatr Blood Cancer 2012;58(05):690-694

4 Maris JM, Hogarty MD, Bagatell R, Cohn SL. Neuroblastoma. Lancet 2007;369(9579):2106-2120

5 Owens C, Irwin M. Neuroblastoma: the impact of biology and cooperation leading to personalized treatments. Crit Rev Clin Lab Sci 2012;49(03):85-115

6 Kleihues P, Cavenee K, eds. Neuroblastic tumours of adrenal gland and sympathetic nervous system. In: Pathology and Genetics of 
Tumours of the Nervous System. Lyon, France: IARC, World Health Organization; 2000:153

7 Kelly DR, Joshi VV. Neuroblastoma and related tumors. In: Parnham DM, ed. Paediatric Neoplasia Morphology and Biology. Philadelphia, PA: Lippincott-Raven; 1996:105-152

8 Ijiri R, Tanaka Y, Kou K, Nishihira H, Nishi T. Bladder origin neuroblastoma detected by mass screening. Urology 1998;52 (06):1139-1141

9 Yokoyama S, Hirakawa H, Ueno S, Yabe H, Hiraoka N. Neuroblastoma of the urinary bladder, preclinically detected by mass screening. Pediatrics 1999;103(05):e67

10 Knoedler CJ, Kay R, Knoedler JP Sr, Wiig TH. Pelvic neuroblastoma. J Urol 1989;141(04):905-907

11 Sáez C, Márquez C, Quiroga E, et al. Neuroblastoma of the urinary bladder in an infant clinically detected by hematuria. Med Pediatr Oncol 2000;35(05):488-492

12 Kojima S, Yagi M, Asagiri K, et al. Infantile neuroblastoma of the urinary bladder detected by hematuria. Pediatr Surg Int 2013;29(07):753-757

13 Zhu J, Hoag NA, Gustafson P, Afshar K, Macneily AE. Pediatric bladder neuroblastoma: case report and literature review. Can Urol Assoc J 2013;7(9-10):E609-E611

14 Hartman C, Williamson AK, Friedman AA, Palmer LS, Fine RG. Bladder ganglioneuroma in a 5-year-old girl presenting with a urinary tract infection and hematuria: case report and review of the literature. Urology 2015;85(02):467-469

15 Cohn SL, Pearson AD, London WB, et al; INRG Task Force. The International Neuroblastoma Risk Group (INRG) classification system: an INRG task force report. J Clin Oncol 2009;27(02): 289-297

16 Shimada H, Ambros IM, Dehner LP, et al. The International neuroblastoma pathology classification (the Shimada system). Cancer 1999;86(02):364-372

17 Brodeur GM, Pritchard J, Berthold F, et al. Revisions of the international criteria for neuroblastoma diagnosis, staging, and response to treatment. J Clin Oncol 1993;11(08):1466-1477

18 Everson TC, Cole WH. Spontaneous regression of malignant disease. J Am Med Assoc 1959;169(15):1758-1759

19 Ghazali S. Pelvic neuroblastoma: a better prognosis. Ann Surg 1974;179(01):115-118

20 Yamamoto K, Hanada R, Kikuchi A, et al. Spontaneous regression of localized neuroblastoma detected by mass screening. J Clin Oncol 1998;16(04):1265-1269

21 Hero B, Simon T, Spitz R, et al. Localized infant neuroblastomas often show spontaneous regression: results of the prospective trials NB95-S and NB97. J Clin Oncol 2008;26(09): 1504-1510 